\title{
Case-Based Review
}

\section{Needle Position Analysis in Cases of Paralysis From Transforaminal Epidurals: Consider Alternative Approaches to Traditional Technique}

Sairam Atluri, MD', Scott E. Glaser, MD², Rinoo Shah, MD³, and Gururau Sudarshan, MD4

From: ${ }^{1}$ Tri-State Spine Care Institute, Cincinnati, $\mathrm{OH}$; ${ }^{2} \mathrm{Pain}$ Specialists of Greater Chicago, Burr Ridge, IL; ' ${ }^{3}$ uthrie Clinic, Horseheads, NY; and ${ }^{4}$ Cincinnati Pain Management Consultants, Cincinnati, $\mathrm{OH}$.

Dr. Atluri is Medical Director, Tri-State Spine Care Institute, Cincinnati, $\mathrm{OH}$.

Dr. Glaser is Medical Director of Pain Specialists of Greater Chicago, Burr Ridge, IL. Dr. Shah is in the Department of Anesthesiology, Guthrie Clinic, Horseheads, NY.

Dr. Sudarshan is Medical Director, Cincinnati Pain Management Consultants, Cincinnati, $\mathrm{OH}$.

Address Correspondence: Sairam Atluri, MD Tristate Pain Management 7655 Five Mile Rd, Suite 117 Cincinnati, $\mathrm{OH} 45230$ E-mail: saiatluri@gmail.com

Disclaimer: There was no external funding in the preparation of this manuscript.

Conflict of interest: None.

Manuscript received: 03-12-2013 Revised manuscript received: 4-25-2013

Accepted for publication: 04-30-2013

Free full manuscript: www.pain physicianjournal.com
Background: Transforaminal technique for epidural steroid injections, unlike other approaches, is uniquely associated with permanent, bilateral, lower extremity paralysis.

Objective: To review the literature and analyze the reported cases of paralysis from lumbar transforaminal epidural steroid injections to possibly establish a cause and to prevent this complication.

Study Design: Eighteen cases of paralysis from transforaminal epidural injection have been reported. We could analyze the position of the needle within the neural foramen based on the available images and/or description among 10 of these 18 cases. Five cases were performed with computed tomography guidance and 12 cases were performed with fluoroscopic guidance [unknown in one case]. Additionally, other variables associated with the procedure, including the technique, were also examined.

Methods: Analysis of the needle position in the neural foramen in cases of paralysis from transforaminal epidural steroid injections. This analysis is based on images and/or description provided in published reports.

Results: Paralysis in these cases seems to be associated with a well performed traditional safe triangle approach with good epidural contrast spreads. Analyzed data shows that $77.7 \%$ of the time, the needle was in the superior part of the foramen. In $71.4 \%$ of the cases, the needle was in the anterior part of the foramen. This coincides with the location of the radicular artery in the foramen. In $22.2 \%$, the needle was in the midzone (neither in the superior nor inferior zone). No level was spared as this event occurred at every foramen from T12 to S1. Ten of these events happened during a left-sided procedure and 8 during a right-sided procedure. No relation to this complication was noted when other variables like type and size of the needles, side of the injection, local anesthetic, contrast, or volume of injectate were taken into consideration.

Limitations: Only 18 cases of paralysis from transforaminal epidurals have been reported. Out of these, only 10 cases included images or descriptions which could be evaluated for our study.

Conclusion: In light of the anatomical and radiological evidence in the literature that radicular arteries dwell in the superior part of the foramen and along with our needle position analysis, we suggest that the traditional technique of placing the needle in the superior and anterior part of the foramen must be reexamined. Alternative, safer techniques must be considered, one of which is described.

Key words: Lumbar epidural injection, lumbar transforaminal, approach, selective nerve root block, paralysis, steroid, particulate, nonparticulate, safe triangle, radicular artery, artery of Adamkiewicz

Pain Physician 2013; 16:321-334 
D isc herniation, discogenic pain, spinal stenosis, radiculitis, and post surgery syndrome are managed with various types of interventional techniques including epidural injections (1-9). In the lumbar spine, access to the epidural space is available by caudal, interlaminar, and transforaminal approaches (1-9). The literature describes substantial differences with the technique and outcomes among the 3 approaches. Overall, utilization of epidural injections in the lumbar spine has been skyrocketing, along with other interventional techniques (10-12). In addition, numerous surgical and nonsurgical interventions have resulted in exploding health care costs (10-32). The literature addressing the effectiveness of spinal interventional techniques continues to emerge, even though it has been debated in reference to appropriate medical necessity and indications (1-9,32-45). Apart from the issues of clinical and cost effectiveness, multiple complications have been described with interventional techniques (1-9,32-37,46-60). Among various approaches utilized in managing epidural injections, transforaminal epidural injections have been considered as target specific and more effective in the past; however, more recent literature shows no significant differences in the outcomes of patients whether receiving caudal epidural, lumbar interlaminar epidural, or transforaminal epidural in reference to disc herniation and spinal stenosis (1-9). Manchikanti et al (11), in an assessment of epidural injections from 2000 to 2011 showed an increase of $130 \%$ per 100,000 Medicare beneficiaries with an annual increase of $7.5 \%$. Above all, this assessment also showed lumbar transforaminal epidural injections increased $665 \%$ from 2000 to 2011 with an annual increase of $20.3 \%$ per 100,000 Medicare beneficiaries (11).

While there is no significant difference in the clinical effectiveness and, presumably, cost utility, transforaminal epidural injections have been associated with a multitude of complications (46-56). Unlike the interlaminar and caudal approaches to the epidural space, the transforaminal approach is uniquely associated with reported complications due to the anatomy related to the radicular artery accompanying the nerve root $(55,57-61)$. Due to the increasing rate of complications, the mechanism of injury has been hypothesized to be embolization, direct injury, muscle spasm, compression, intimal flaps, and transection of either the artery of Adamkiewicz or the radicular artery. Consequently, multiple anatomic studies, as well as various approaches considered as safer have been described
(55,57-69). Thus, the overall mechanism has been postulated to be the damage to the radicular artery based on its size which is similar to that of a 22 gauge spinal needle - commonly used in performing transforaminal epidural injections.

However, there has not been a systematic assessment of the complications and causes for the complications, along with the role of alternate techniques in performing these procedures safely. Consequently, this analysis was undertaken by literature assessment.

\section{Methods}

The literature search was carried out utilizing multiple electronic databases including PubMed, Cochrane reviews, review of systematic reviews, book chapters, and related articles extending from 1966 through February 2013. The key search terms utilized were transforaminal epidural, selective nerve root block, paralysis, paresis, steroid, artery of Adamkiewicz, radicular artery, safe triangle, unsafe triangle, and spinal cord infarct. Cited references of the relevant published articles were reviewed. The literature search produced over 400 manuscripts of which 11 publications were found reporting a total of 18 cases (46-56).

We analyzed the images/descriptions of the published cases of paralysis resulting from lumbar transforaminal epidurals in order to find a pattern in the needle placement, if any, which was consistent with this complication. Images or descriptions of the procedure were not available for all reported cases. Houten and Errico (46) did not provide any images of the 3 cases that they reported. They described the needle placement as "placement of the needle tip at the point where the nerve root emerges from the neural foramen." We felt that this was not enough information to assess the precise location of the needle in the foramen and hence these 3 cases were excluded in our analysis. Huntoon and Martin (47) did not provide an image or description and we were not able to include this case in our study. Wybier et al (53) reported 5 cases, but only 3 were transforaminal injections (one was after interlaminar epidural injection and the other was after intraarticular facet joint injection). Among these 3 transforaminal injections only one had an image/description. Glaser and Shah (54) reported 3 cases, but details were provided in only one case. Hence, information could be gathered from only 10 of the 18 reported cases. Images were provided in 9 of the cases and description was used in one case (60). In one case, we used both the image and description (51). We reached out to all the authors. Ten out of the 11 authors 
communicated back and informed us that other images were not available (46-55). Among the eligible cases, we specifically examined whether the needle placement was in the superior, inferior, anterior, posterior, medial, or lateral part of the foramina. The location of the needle in the foramina was determined independently by the authors who are experienced in the performance of this procedure. If there was a disagreement, it was resolved by discussion. Eight authors who responded to us agreed with our assessment of the needle position in their case reports (46-55). One author did not respond to our query about needle location (53). Another author responded but did not want to comment on our interpretation of the needle position (56).

Superior and inferior needle location was checked in the lateral and anteroposterior (AP) view of the fluoroscopic images. The foramen was measured from the bottom of the superior pedicle to the top of the inferior pedicle. This zone was divided into superior, mid, and inferior portions. For the medial/lateral plane, the area of interest was the space between the 6 o'clock position on the interested pedicle and the lateral aspect of the pedicle (9 o'clock on the left pedicle and 3 o'clock on the right pedicle) using both AP views on fluoroscopy and axial views on computed tomography (CT). This zone was vertically bisected. Needle positioning at, or medial to, the bisecting line was deemed medial and if the needle was lateral to this line, it was determined as lateral positioning. For checking anterior or posterior placement, both lateral views on fluoroscopy and axial views on CT were utilized. In these views the foramen was divided into anterior and posterior halves and then the needle location was assessed. Three zones (superior, mid, inferior) were chosen in the superoinferior plane and only 2 zones for anteroposterior plane and mediolateral plane. This is because the superoinferior plane is much larger compared to the other 2 planes.

\section{Results}

Our analysis of the needle positioning in the foramen is detailed in Table 1. Among 10 cases, the needle position could be determined whether it was in the su-

Table 1. Description of location of needle placement.

\begin{tabular}{|c|c|c|c|c|c|c|c|c|c|}
\hline Author/Year & Superior & Inferior & Anterior & Posterior & Medial & Lateral & Ar4 & Ai5 & Aa6 \\
\hline \multirow{3}{*}{ Houten \& Errico (46) } & NI1 & NI & NI & NI & NI & $\mathrm{NI}$ & Yes & No & Yes \\
\hline & NI & NI & NI & NI & NI & NI & & & \\
\hline & NI & NI & NI & NI & NI & NI & & & \\
\hline Glaser \& Falco (48) & Yes & No & Yes & No & Yes & No & Yes & No & Yes \\
\hline Huntoon \& Martin (47) & NI & $\mathrm{NI}$ & NI & NI & NI & NI & Yes & No & Yes \\
\hline Somayaji et al (49) & UNK & UNK & No & Yes & No & Yes & Yes & No & Yes \\
\hline Quintero et al (50) & Yes & No & No & Yes & UNK & UNK & No & N/A & N/A \\
\hline \multirow{2}{*}{ Kennedy et al (51) } & Yes & No & UNK & UNK & No & Yes & Yes & No & Yes \\
\hline & Yes & No & Yes & No & Yes & No & Yes & No & Yes \\
\hline Lyders \& Morris (52) & Yes & No & UNK & UNK & UNK & UNK & Yes & No & Yes \\
\hline \multirow{3}{*}{ Wybier et al (53) } & Mid & Mid & UNK & UNK & No & Yes & Yes & No & Yes \\
\hline & NI & NI & NI & NI & NI & NI & & & \\
\hline & NI & NI & NI & $\mathrm{NI}$ & NI & NI & & & \\
\hline \multirow{3}{*}{ Glaser \& Shah (54) } & Yes & No & Yes & No & UNK & UNK & Yes & No & Yes \\
\hline & NI & NI & NI & NI & NI & NI & Yes & No & Yes \\
\hline & NI & $\mathrm{NI}$ & NI & NI & NI & NI & Yes & No & Yes \\
\hline Murthy et al (55) & Yes & No & Yes & No & Yes & No & Yes & No & Yes \\
\hline \multirow[t]{2}{*}{ Chang Chien et al (56) } & Mid & Mid & Yes & No & Yes & No & Yes & No & Nc9 \\
\hline & $\begin{array}{c}\text { IKC8 7/9 } \\
(77.7 \%)\end{array}$ & $\begin{array}{c}\text { IKC } 0 / 9 \\
(0 \%)\end{array}$ & $\begin{array}{l}\text { IKC 5/7 } \\
(71.4 \%)\end{array}$ & $\begin{array}{l}\text { IKC 2/7 } \\
(28.5 \%)\end{array}$ & $\begin{array}{l}\text { IKC } 4 / 7 \\
(57.1 \%)\end{array}$ & $\begin{array}{l}\text { IKC 3/7 } \\
(42.8 \%)\end{array}$ & & & \\
\hline
\end{tabular}

$\mathrm{NI}=$ No information available; UNK = Unknown based on image reivew and/or description; AR = Author responded; AI = Additional images available; $\mathrm{AA}=$ Author agreed with our assessment; $\mathrm{NR}=$ No response; $\mathrm{IKC}=\mathrm{In}$ known cases; $\mathrm{Mid}=$ midzone 
perior or the inferior part of the foramen in 9 cases. In 7 out of these 9 cases $(77.7 \%)$, the needle tip was in the superior part of the foramen. In 2 out of 9 cases $(22.2 \%)$, the needle tip was in the midzone (neither superior nor inferior). Needle position (if superior or inferior) could not be determined in one case (47). In all 9 cases where the needle position could be verified, none had needle placement in the inferior part of the foramen. In $71.4 \%$ and $28.5 \%$ of the cases, the needle was in the anterior part and posterior part of the foramen, respectively. In $57.1 \%$ of the cases when the needle position could be analyzed, it was in the medial part, and in the other $42.8 \%$ it was in the lateral part.

As shown in Table 2, no relation to this complication was noted when other variables like size of needles, local anesthetic, contrast, or volume of injectate were analyzed among these cases. In 5 cases CT guidance was used and in 12 cases, fluoroscopy was utilized.

Non-particulate steroids were not used in any case. In 3 cases, real time fluoroscopy was done during contrast injection $(48,51,56)$. In one case, paralysis ensued despite using the "test dose" and digital subtraction (56). Contrast was injected in all but 2 cases $(49,50)$. In one case, the artery of Adamkiewicz was at the L3 level and the injection was done at the L5 foramen (53). No level was spared as this event occurred at every foramen from T12 to S1 (Table 3).

\section{Discussion}

The results of this systematic assessment of the available literature regarding transforaminal epidural injections with major neurological complications showed that in 7 out of the 9 cases $(77.7 \%)$ the needle tip was in the superior part of the foramen, whereas in 2 out of 9 cases $(22.2 \%)$ the needle tip was in the mid zone. In $71.4 \%$ and $28.5 \%$ of the cases, the needle was in the anterior part and posterior part of the foramen, respectively. The needle position was in the medial part in $57 \%$ of the cases and the lateral part in $43 \%$ of the cases among the cases where appropriate images were available. This systematic assessment demonstrated the relationship to the needle position without any significant relation to other variables such as needle size, local anesthetic injected, contrast, or volume of injectate. There was no significant difference between types of image guidance with 5 cases performed with CT guidance and 12 cases under fluoroscopy. Surprisingly, during 2008 , only $0.4 \%$ of cases were performed with CT, but $29 \%$ of cases of paralysis were under CT. All patients received particulate steroids. Multiple hypothesis have been forwarded in reference to the occurrence of thrombosis or embolic phenomenon, including position of the needle, particulate steroid, type of the needle, and various modifications of techniques to safely perform these procedures. However, there is a paucity of literature describing all of the above aspects considering this is an extremely unusual complication.

Review of anatomical studies shows that the radicular artery seems to be located predominantly in the superior part of the neural foramen. In a cadaveric microsurgical anatomical study, Alleyne et al (57) found that the artery of Adamkiewicz was consistently found at the superior or middle portion of the foramen, ventral and slightly rostral or ventral to the dorsal root ganglion-ventral root complex (DRG-VR). Kroszczynski et al (58) showed in a cadaveric study that the artery of Adamkiewicz and radicular arteries were predominantly located in the upper one-third of the foramen, anterosuperior or anterior to the DRG-VR complex. They found that $74 \%$ of the radicular arteries reside in the upper one-third of the foramen compared to $23 \%$ in the mid one-third of the foramen. Only $3 \%$ of the radicular arteries lie in the inferior one-third. The average distance from the superior pedicle to the artery was $1.2 \mathrm{~mm}$ and was $5.09 \mathrm{~mm}$ from the inferior pedicle. Rauschning (59) reported that the nerve root complex (root sleeve, ganglion, and nerve trunk) invariably lies in the "subpedicular notch" (which is the superior part of the foramen) together with the branches of lumbar artery implying superior location. van Roy et al (60) in an anatomical review stated that the radicular artery follows the cranial aspect of the spinal nerves which reside in the large upper part of the foramen.

Radiological evidence also confirms that the radicular arteries reside mostly in the superior part of the foramen. Murthy et al (55) evaluated 113 radiculomedullary arteries in the intervertebral foramen and reported that $88 \%$ of them are in the superior third of the neural foramen as opposed to only $9 \%$ and $2 \%$ in the mid and inferior third, respectively. No radicular arteries were found in the lower fifth of the foramen. Further, more arteries were found in the mid and inferior part of the superior zone, when compared to the superior part of the superior zone. Takase et al (61) traced the artery of Adamkiewicz from the aorta to the anterior spinal artery using CT. In 43 of the 63 patients, they could completely visualize the artery along its course except at the intervertebral foramen because it was too close to the "bone" in the foramina. Personal communication with the author (Dr. Takase) confirmed that this "bone" 


\begin{tabular}{|c|c|c|c|c|c|c|c|c|c|}
\hline 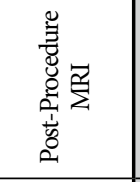 & 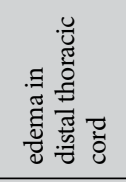 & 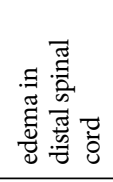 & 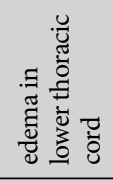 & 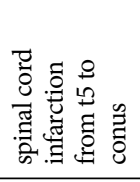 & 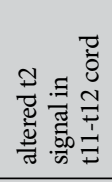 & 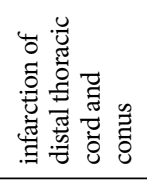 & 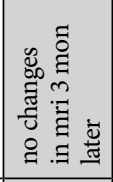 & 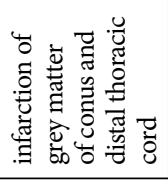 & 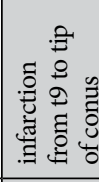 \\
\hline 莺 & 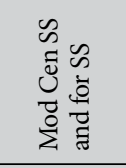 & 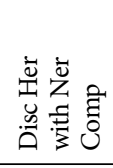 & $\begin{array}{l}\vec{z} \\
\text { हे } \\
\text { के }\end{array}$ & 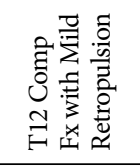 & 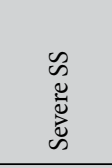 & 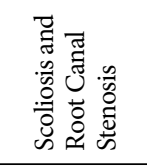 & 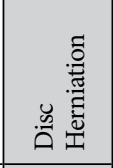 & 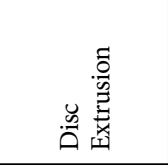 & $\bar{z}$ \\
\hline 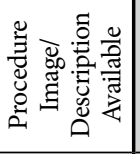 & $\stackrel{\circ}{z}$ & z & $\stackrel{\circ}{z}$ & 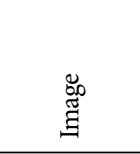 & $\stackrel{\circ}{z}$ & $\begin{array}{l}\text { 品 } \\
\text { 品 }\end{array}$ & 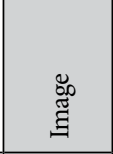 & $\begin{array}{l}\text { 品 } \\
\text { 囦 }\end{array}$ & 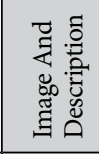 \\
\hline 总慁领 & $\stackrel{\approx}{\approx}$ & $\cong$ & $\cong$ & ż & $\cong$ & $\bar{z}$ & $\stackrel{\circ}{ }$ & z & $\dddot{x}$ \\
\hline 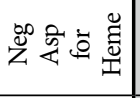 & $\cong$ & $\cong$ & $\approx$ & 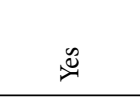 & $\bar{z}$ & $\bar{z}$ & 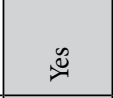 & $\bar{z}$ & $\bar{z}$ \\
\hline 90 & ż & そ̊ & そ̊ & $\Psi$ & $\bar{z}$ & そ̊ & そ̊ & $\Psi$ & $\bar{z}$ \\
\hline 岂 & $\ddot{0}$ & 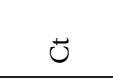 & む & 山 & ш & $\ddot{0}$ & 山 & 山 & $\ddot{0}$ \\
\hline $\begin{array}{l}\text { च्च } \\
\check{\check{z}}\end{array}$ & 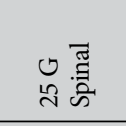 & ن & 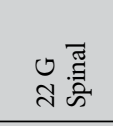 & 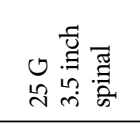 & 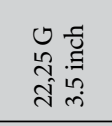 & $\begin{array}{l}0 . \bar{\Xi} \\
\vec{n} \text { के }\end{array}$ & $\begin{array}{l}0 \\
\text { i }\end{array}$ & 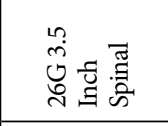 & 어욤 \\
\hline 㺼: & ह్ & 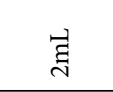 & ్ㅠ & 馬 & $\sum_{i n}$ & $\underset{N}{\vec{j}}$ & $\bar{z}$ & $\sum_{i}^{H}$ & $\underset{\Delta}{\Delta}$ \\
\hline 芯营 & $\begin{array}{l}\overline{8} \\
8 \\
\end{array}$ & $\overrightarrow{8}$ & ت & $\overrightarrow{8}$ & $\begin{array}{l}\overline{8} \\
0 \\
\end{array}$ & $\bar{z}$ & 气̆ & $\bar{z}$ & $\bar{z}$ \\
\hline 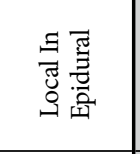 & 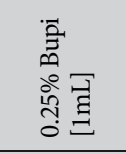 & 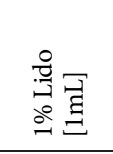 & 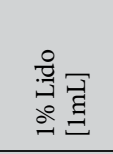 & 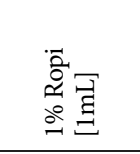 & 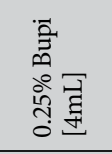 & 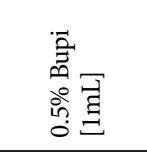 & $\bar{z}$ & 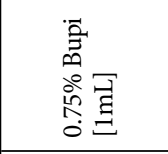 & 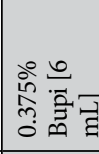 \\
\hline ڤે & 音互 & 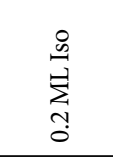 & $\begin{array}{l}\text { 莣 } \\
\text { 局 } \\
\text { क् } \\
\end{array}$ & 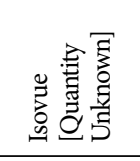 & $\begin{array}{l}\bar{\Xi} \\
\vdots \\
\vdots \\
\\
\end{array}$ & $\bar{z}$ & 亏ั̆ & 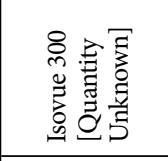 & 离 \\
\hline 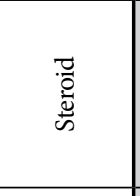 & 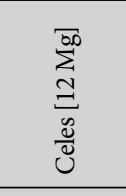 & 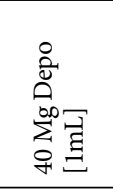 & 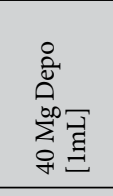 & 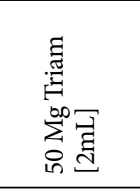 & 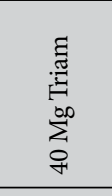 & 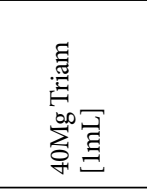 & 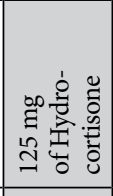 & 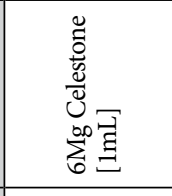 & 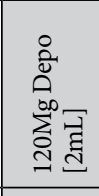 \\
\hline 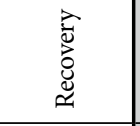 & 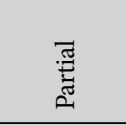 & $\stackrel{8}{ }$ & $\stackrel{\circ}{z}$ & ż & $\stackrel{8}{z}$ & 息 & 卺 & 呇 & $\bar{z}$ \\
\hline 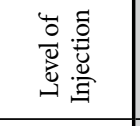 & 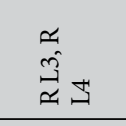 & $\stackrel{3}{3}$ & $\vec{\omega}$ & $\stackrel{I}{\stackrel{I}{H}}$ & $\exists$ & $\underset{3}{3}$ & $\underset{\exists}{\leftrightarrows}$ & $\stackrel{3}{3}$ & $\stackrel{3}{a}$ \\
\hline 总苨 & 鸢 & 訔 & $\sum_{\nexists}$ & $\frac{1}{6}$ & $\sum_{\delta}$ & $\underset{⿱}{\stackrel{2}{*}}$ & 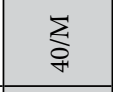 & $\underset{\infty}{\stackrel{\omega}{\infty}}$ & $\frac{\sum}{\Omega}$ \\
\hline $\begin{array}{l}\text { 苛 } \\
\text { 壳 }\end{array}$ & 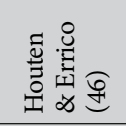 & 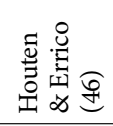 & 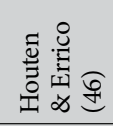 & 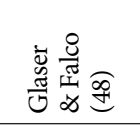 & 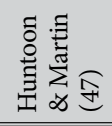 & 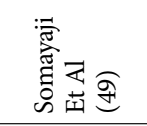 & 离 & 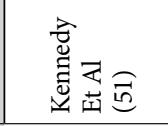 & 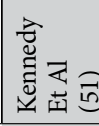 \\
\hline
\end{tabular}


Pain Physician: July/August 2013; 16:321-334

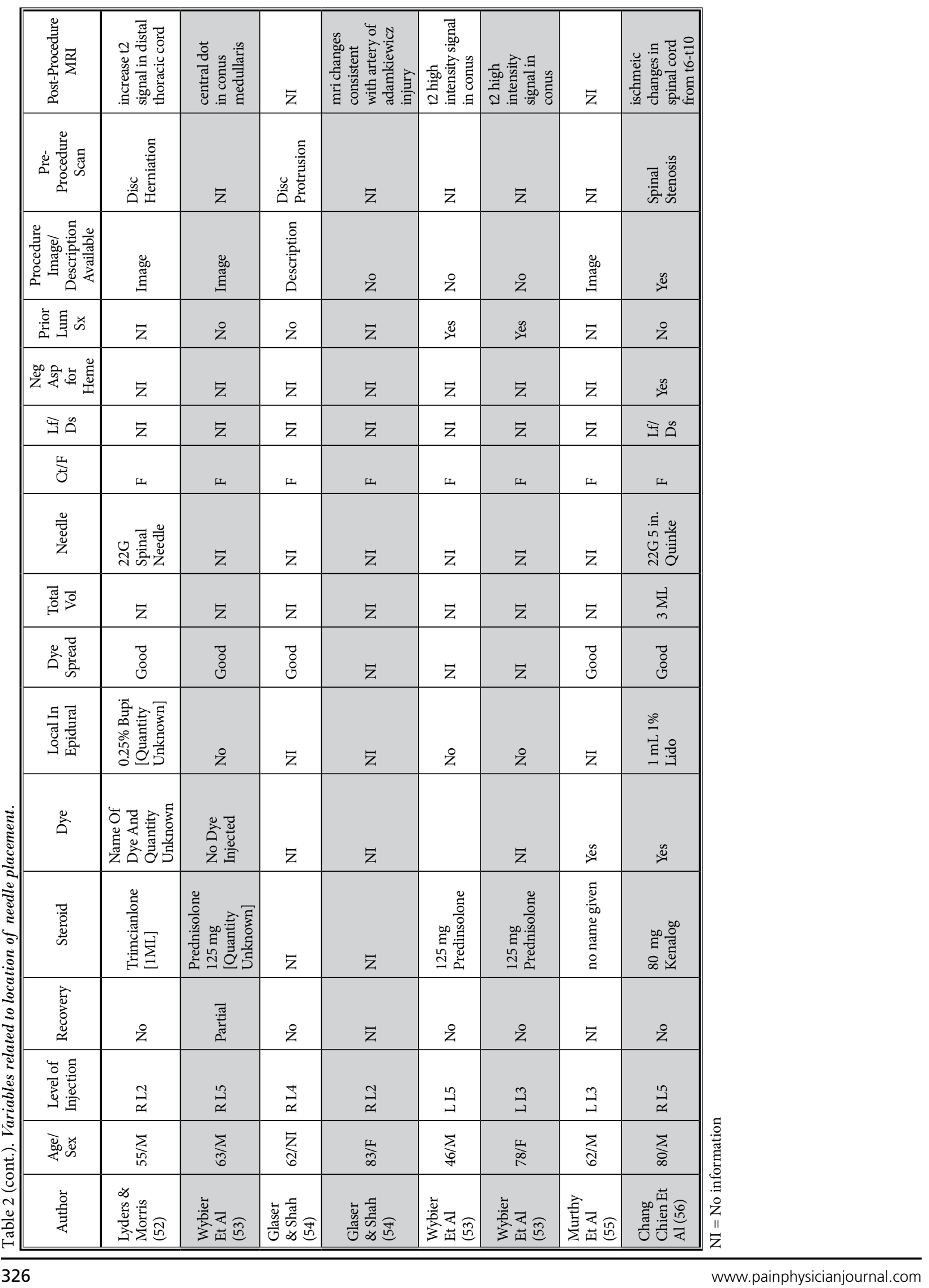


was in fact the medial and inferior part of the pedicle. In other words, $68 \%$ of the time, the artery is hugging the pedicle in the superior part of the foramen. In addition, according to Kroszczynski et al (58), based on a cadaveric study, the artery is anterosuperior to the nerve in $54 \%$, anterior to the nerve in $41 \%$, and anteroinferior to the nerve in $5 \%$ of the specimens. Krowyinski et al (58) also suggested that the artery is either superior or superoanterior to the nerve in the foramen. Alleyne et al (57) reported that the artery of Adamkiewicz lies at the superior and ventral aspect of the nerve.

The ischemic complications seem to occur in cases of needles placed in the superoanterior part of the foramen (where the radicular artery usually resides) using the TSTT Traditional safe triangle technique (TSTT) associated with good reported and observed contrast spreads. Glaser and Falco (48) were the first to question the TSTT. They suggested that the needle should be placed in the inferior and anterior part of the foramen. Jasper (62) described the above technique more elaborately and named it "retrodiscal transforaminal" injection. Lee et al (63) have also critiqued the TSTT, questioning the need to cross the nerve in order to place the needle anteriorly in the foramen. They proposed an alternative approach placing the needle in the superoposterior part of the foramen. Murthy et al (55) also advocated inferior placement of the needle in the foramen, posterior to the nerve. Glaser and Shah (54) went to the extent of stating that the TSTT is not safe. They advocated targeting Kambin's triangle--the inferoanterior aspect of the foramen. More recently Zhu et al (64) proposed placing the needle in the posterior part of the foramen. The common denominator for all these alternative approaches is avoidance of the superoanterior part of the foramen.

The anatomical and radiological studies, along with our clinical study, suggest that the radicular artery rarely lies in the inferior part of the foramen (Table 4). Therefore, it seems prudent to place the needle in the inferior part of the foramen. Additionally, in our study, none of the paralysed cases had inferior needle placement. One disadvantage of the inferior placement is that it increases the chances of the medication spread to the inferior nerve root. Unlike superior placement, inferior needle placement has a risk of disc entry (54). Because the artery of Adamkiewicz and the radicular arteries are anterior or superior to the nerve $(55,57,58)$, placing the needle in the mid or posterior part of the foramen (posterior to the nerve) may offer additional assurance. Also, the dorsal root ganglion/dorsal root is in the $\mathrm{mid} /$ posterior part of the foramen. Steroid application as close as possible to this important structure may theoretically be more beneficial than in the ventral epidural space. In our analysis, in 5 of the 7 cases, the needle was in the anterior part of the foramen, and in 2 of the 7 cases, needle placement was posterior. In at least one of the 2 posterior placements, the needle was also in the superior part. In the other posterior case, the superior or inferior location could not be determined based on the information provided. Posterior placement is a less painful procedure as the needle is not traversing the nerve contrary to the traditional technique.

Based on our analysis of the available anatomical studies and radiological studies, we have identified the "Inferior Triangle." In the oblique fluoroscopic view, its boundaries are as follows: The lateral border of the superior articular process forms one side of the triangle and the transverse process is the base. The hypotenuse is the traversing nerve. This is diametrically opposite of the traditional Safe Triangle (Fig. 1). We propose to place the needle as inferior and as posterior as possible in the neural foramen which corresponds to the

Table 3. Correlation of level of injection with complications.

\begin{tabular}{|c|c|}
\hline Level of Procedure & Reported Cases \\
\hline T12 & 1 \\
\hline L1 & 1 \\
\hline L2 & 2 \\
\hline L3 & 5 \\
\hline L4 & 3 \\
\hline L5 & 2 \\
\hline S1 & 1 \\
\hline
\end{tabular}

Table 4. Descriptions of location of the radicular artery in the foramen.

\begin{tabular}{|l|c|c|c|c|c|c||}
\hline \multicolumn{1}{|c|}{ Study } & Superior & Inferior & Anterior & Posterior & Medial & Lateral \\
\hline Murthy et al (55) & 88 & 2 & NI & NI & NI & NI \\
\hline Kroszczynski et al (58) & 74 & 3 & NI & NI & NI & NI \\
\hline Takase et al (61) & 68 & NI & NI & NI & NI & NI \\
\hline
\end{tabular}

$\mathrm{NI}=$ No information 


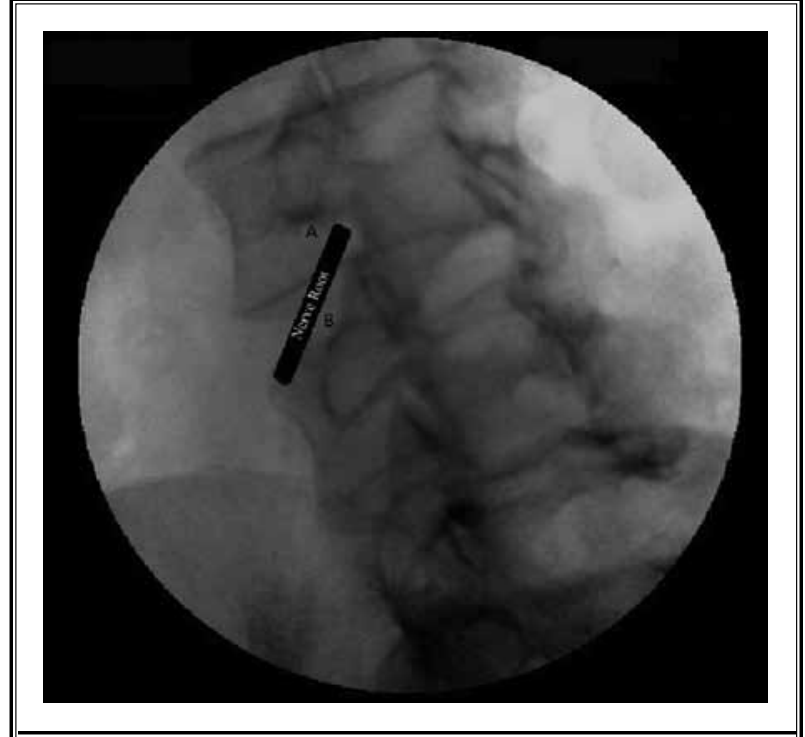

Fig. 1. A- Traditional safe triangle technique. B-Inferior triangle technique.

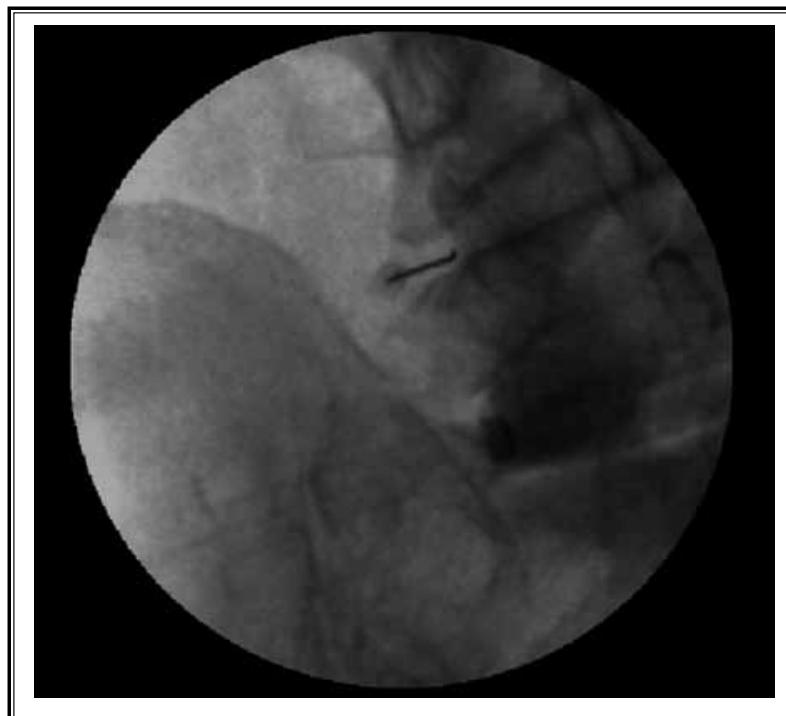

Fig. 3. Needle walked off the junction of superior articular process and transverse process by a few millimeters.

inferomedial part of this Inferior Triangle. The C-ARM should be oblique ipsilaterally until the "target point" is seen. The target point is the junction of superior articular process (SAP) and transverse process (TP) (Fig. 2). If this landmark is not clearly visualized, alternatively the inferolateral part of the SAP can be targeted. Craniocaudal angulation of the C-ARM may be required to "crisp up" these target points. Targeting either of these

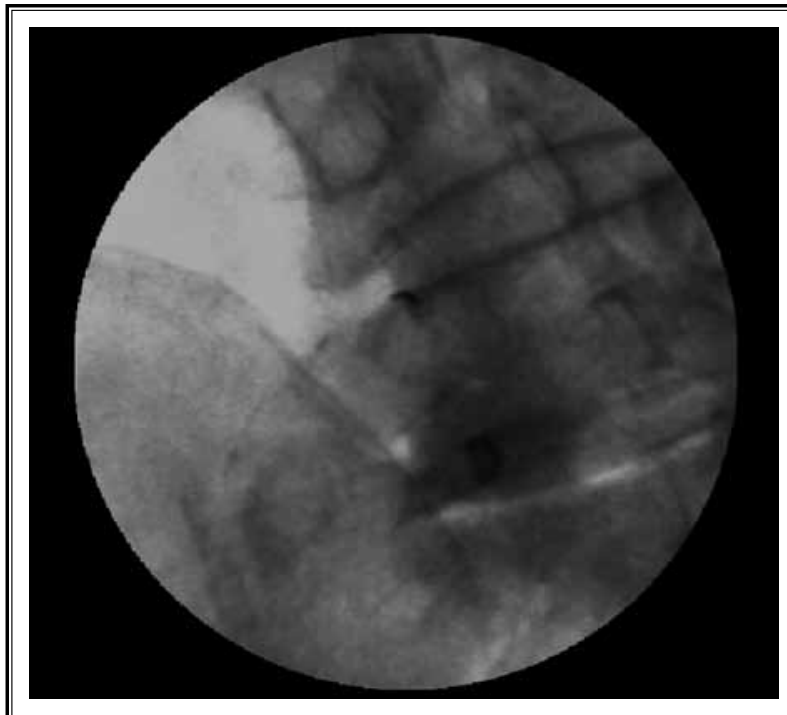

Fig. 2. Needle placed to contact the junction of superior articular process and transverse process. Alternatively it can be placed at the inferolateral part of the superior articular process.

points is critical as it will ensure inferior placement of the needle in the foramen. If not, the likelihood of the needle placement in the midzone of the foramen increases. This is not ideally desirable as up to $23 \%$ (59) and $9 \%(67)$ of the time, the radicular artery lays in the midzone of the foramen. Alleyne et al (63) reported that the radicular artery can also dwell in the midzone. In fact, in 2 of the cases we analyzed, the needle was in the midzone $(59,62)$. If an L3 transforaminal epidural is planned, the target point is the junction of the SAP with TP at L4 level and not L3. Place the needle using the "gun barrel" technique to contact the junction of SAP and TP (or the inferolateral part of SAP) (Fig. 2). After contacting either one of the above landmarks (this will ensure posterior placement of the needle and also decreases the chances of inadvertently entering the disc), walk off the bone slightly into the foramen (Fig. 3). Check the lateral view and advance the needle if necessary until it is in the posterior part of the foramen (Fig. 4). Move the C-ARM to visualize the AP view. Make sure that the needle tip is at the lateral aspect of the pedicle (Fig. 5). Inject dye under real time fluoroscopy (using AP views) and check for any vascular spread and also for medial epidural spread (Fig. 6). If the desired medial epidural spread is not achieved, then advance needle slightly (keep the needle bent medially if using a curved needle) and inject again and repeat this process until good medial epidural spread is obtained (make 


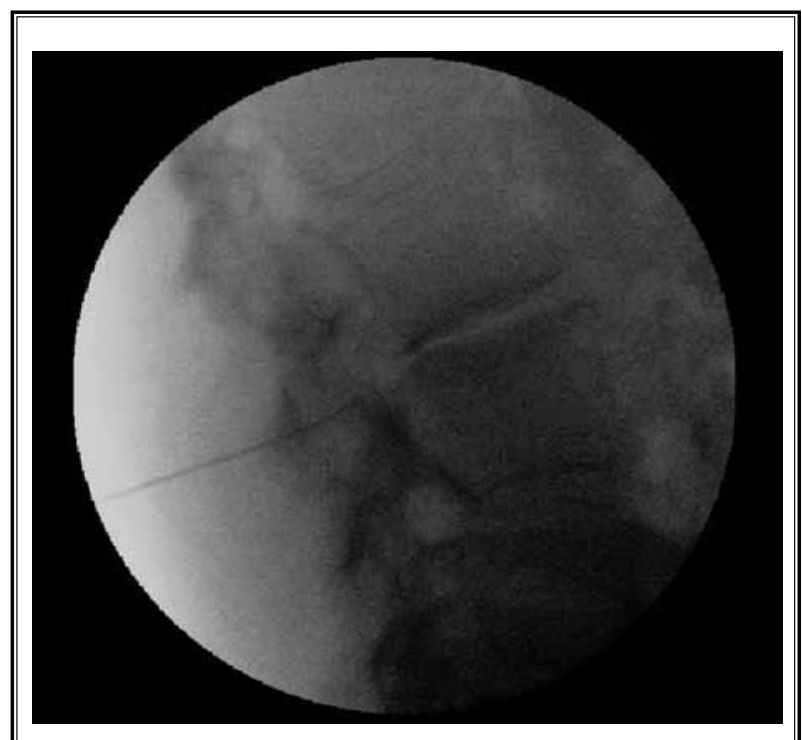

Fig. 4. Lateral view is checked to ensure that the needle tip is in the posterior part of the foramen.

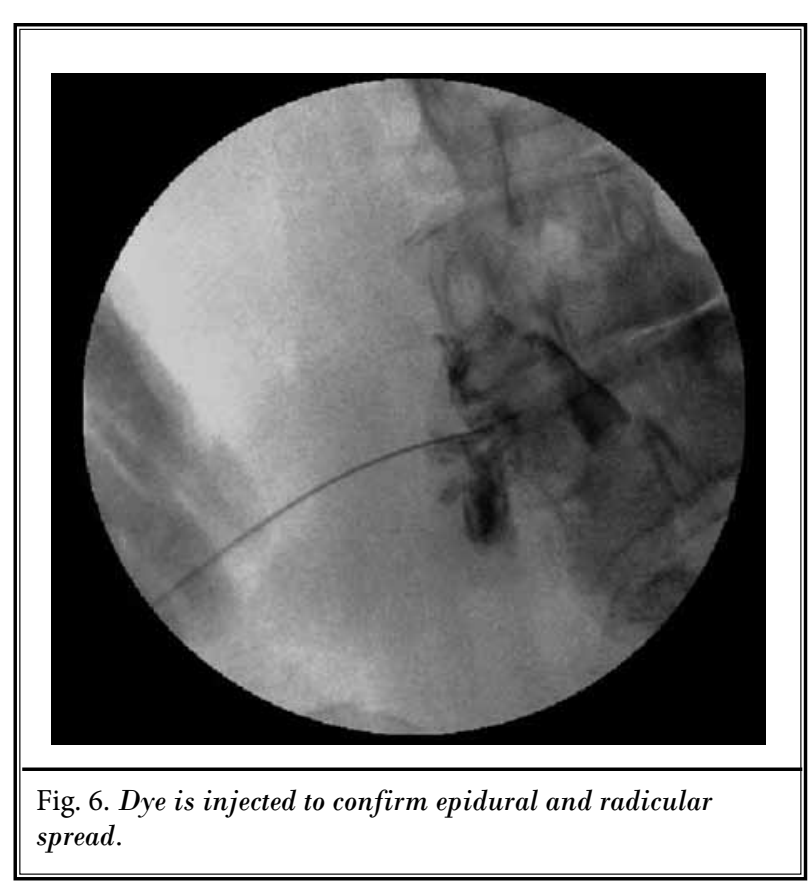

sure that it is not medial to the 6 o'clock of the pedicle to avoid subdural/intrathecal or intradiscal placement). As soon as the initial medial contrast spread is seen (even though lateral spread is noted), cease further needle advancement because staying as lateral as possible in the AP view will ensure posterior placement of the needle in the foramen. Although in most cases

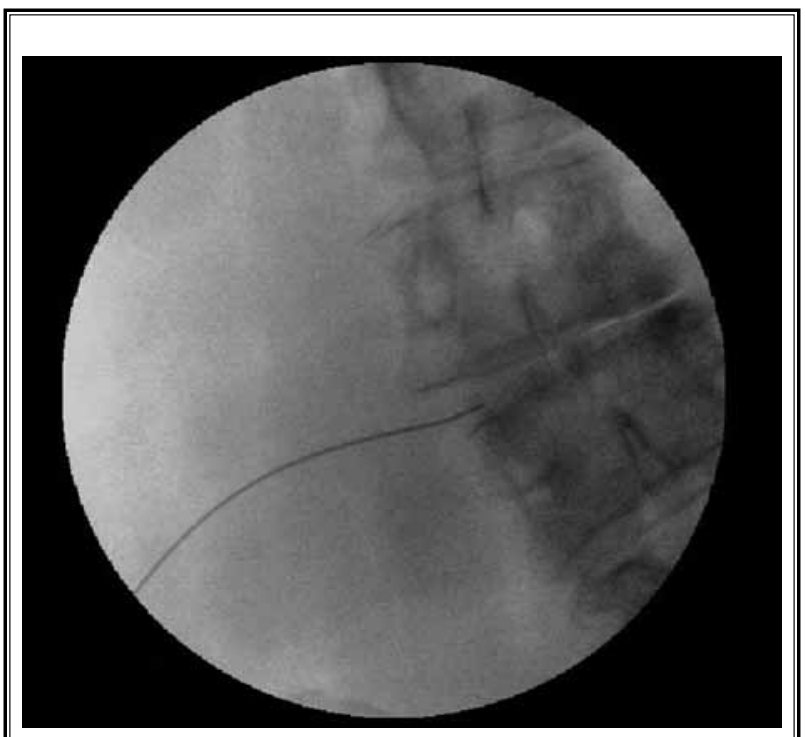

Fig. 5. AP view is checked to make sure that the needle tip is at the lateral part of the pedicle.

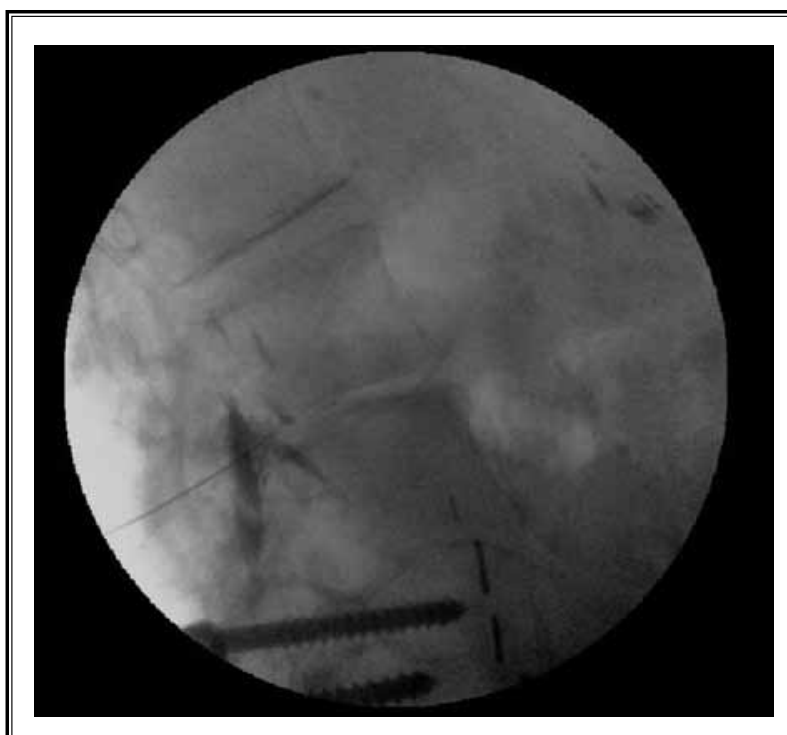

Fig. 7. To achieve epidural spread sometimes the needle tip may have to be advanced to the anterior part of the neural foramen. In such cases, it is advised to make sure that the needle is in the inferior part of the foramen.

medial contrast spread can be achieved in the posterior part of the foramen, sometimes the needle may have to be advanced to the anterior part of the foramen (Fig. 7). If the needle is in the anterior part of the foramen, it is pertinent that it should be in the inferior part. If not, the needle has to be repositioned. After 


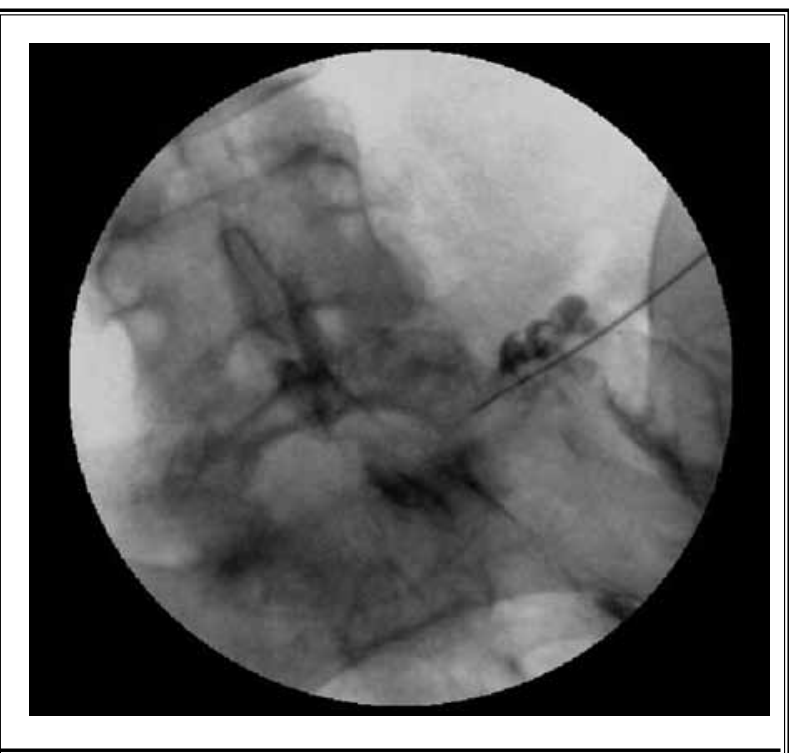

Fig. 8. In spite of some difficulty because of the iliac crest, this procedure can be done even at L5 level.

negative aspiration for blood and cerebrospinal fluid and also negative vascular and intrathecal/subdural contrast spread (under real time fluoroscopy), inject the medication. The inferior approach, unlike the superior approach, unfortunately increases the likelihood of encountering the disc (46). Although the frequency of disc encounter is higher in the inferior technique compared to the traditional technique, the incidence is very low. It is less than $2 \%$ in our experience. These are probably intra-annular injections and not intranuclear injections. Staying posteriorly in the foramen will eliminate this risk. Anecdotally, we have seen a few interannular dye spreads using the inferior approach without any discitis as these procedures should be done in sterile conditions. Another concern is the possibility that annular puncture can predispose disc herniation. Although possible, it is probably rare as there is no evidence that even discograms (which are more intrusive) cause disc herniations. This approach can also be done at the L5 level at the junction of SAP and sacral ala (Fig. 8). Good epidural contrast spreads were also achieved by placing the needle in the midzone (superoinferior plane) and posteriorly in the foramen. If this approach is contemplated, it is paramount that the needle is absolutely in the posterior part of the foramen (Fig. 9). A superoposterior approach may also mitigate the risk of paralysis, but emphasis should be placed on the needle being absolutely posterior. This approach may be useful in cases where because of either severe foraminal stenosis

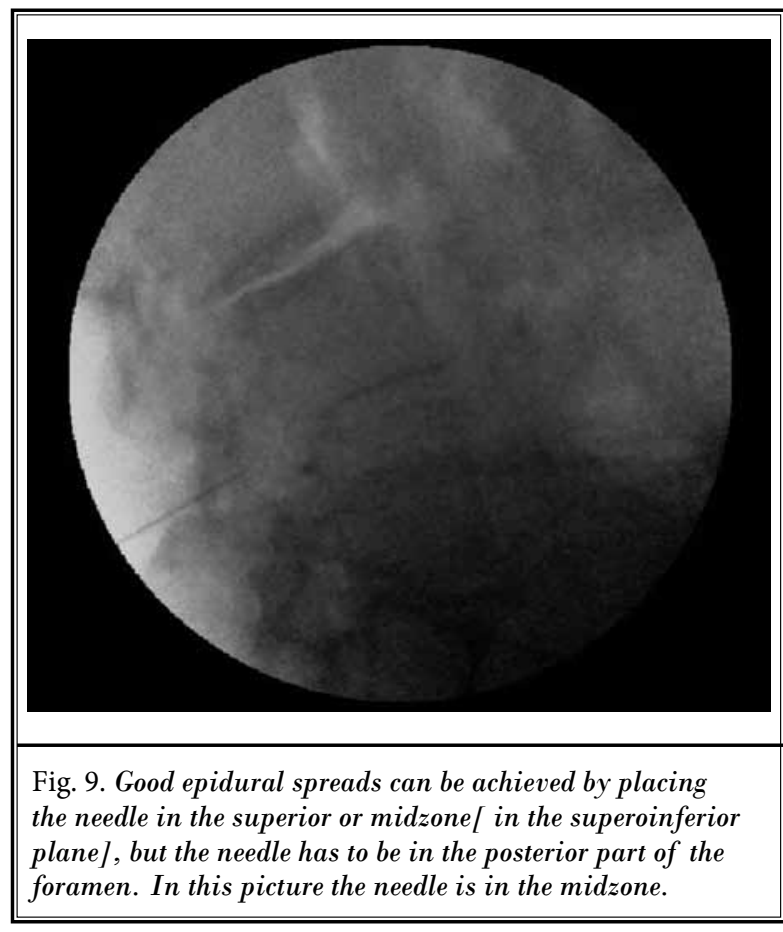

or other anatomical variables, it is difficult to place the needle in the inferior part of the foramen. It is also useful in selective nerve root blocks as inferior spread of the injectate is not desirable. Sometimes during an attempt for inferior placement, the needle course may deviate towards the superior part of the foramen. In such cases precaution should be taken to make sure the needle is in the posterior part of the foramen.

Systematic reviews of the published data and studies have shown that lumbar transforaminal epidural steroid injections (LTESI) are effective in reducing pain, improving function, and decreasing surgery and costs $(2,6,7,45)$. Accordingly, there has been an explosive growth in the utilization of these procedures (10-12). Although LTESI can be done safely without major complications (37), this particular complication deserves special attention. Our view is that in order to decrease the risk of paralysis, the TSTT approach must be reconsidered. One could argue that the majority of the cases with paraplegia had needle placement in the superior foramen because it is the most common placement currently. But with all the anatomic and radiologic data showing that the radicular artery dwells most commonly in the superior part of the foramen, it seems prudent to avoid this location. Consideration should be given to replace the traditional method by the other techniques described above or others in the past which 
avoids the anterosuperior part of the foramen (Table 5) $(48,54,55,62-64)$. The safety of these newer techniques is not known but they appear to be safer than the traditional approach based on the anatomical, radiological, and now the clinical evidence that the radicular artery rarely resides in the inferior part of the foramen. Recent studies (65-69) have shown that by using the inferior approach as described by Glaser and Shah (54) and the retrodiscal approach advocated by Jasper (62), results similar to the traditional technique have been achieved with less neural contact. By extrapolation, decreasing neural contact possibly means reducing radicular artery contact because the nerve root and radicular artery dwell intimately in the neural foramen. However, one study (70) found that the pain relief was superior when the superior-anterior approach was compared to the superior-posterior technique.

There is an argument that replacing particulate steroids with nonparticulate dexamethasone will avoid an embolization event but it won't thwart injury from needle trauma or spasm of the artery. Avoiding the artery seems more prudent than using nonparticulate steroids. Theoretically, particulate steroids seem to be more efficacious than nonparticulate steroids. Some have advocated measures like using digital subtraction, dye injection using real time fluoroscopy, using blunt needles, and using test doses before injecting steroid $(51,71)$. One case of paralysis has been reported in spite of using a test dose and digital subtraction (56). However, avoiding the TSTT, in our opinion, is possibly more reliable to avoid future catastrophic complications. Since the entry level of the major radicular artery is so variable and complications were seen as low as $L 5$ and $\mathrm{S} 1$, no level is immune and every level should be treated with caution (Table 3). In one case (53), the artery of Adamkiewicz was at the L3 level and the patient experienced paraplegia during an $\mathrm{L} 5$ injection. This leads us to believe that every radicular artery needs to be respected. Although LTESI is a commonly done procedure, paralysis from it is very rare because not all radicular arteries reach the anterior spinal artery to reinforce it $(52,72)$. Out of the 62 radicular arteries (31 pairs) in the entire spine, only 7 or 8 participate in vascularization of the spinal cord (72). They are less frequent in the lumbar region. In the study by Murthy et al (55), among 115 patients, only 2 patients had an additional radiculomedullary artery apart from the artery of Adamkiewicz and one patient had 2 additional radiculomedullary
Table 5. Description of alternate positions to increase safety.

\begin{tabular}{|l|c|}
\hline Authors & Needle Location in Foramen \\
\hline Murthy et al (55) & Inferior and Posterior \\
\hline Glaser and Shah (54) & Inferior and Anterior \\
\hline Lee et al (63) & Superior and Posterior \\
\hline Jasper (62) & Inferior and Anterior \\
\hline Glaser and Falco (48) & Inferior and Anterior \\
\hline
\end{tabular}

arteries. However in Kroszczynski et al's study (58) in 24 cadavers, there were 23 arteries of Adamkiewicz and 16 radiculomedullary arteries which reinforced the spinal artery. Interestingly, $37.5 \%$ of the radiculomedullary arteries in this study were found in the middle part of the foramen (in the superoinferior plane) in comparison to only $13 \%$ of the arteries of Adamkiewicz. Compromise of any of these arteries can cause paralysis. Unfortunately, we do not know ahead of time at which lumbar level and on which side these arteries dwell in the lumbar spine although they are more commonly seen on the left side above the L3 level. This forces us to respect every level and side. Intravascular penetration is not uncommon during transforaminal epidurals (73-75).

Some studies have occasionally reported better outcomes with transforaminal epidurals when compared to the interlaminar approach probably vindicating their selective nature (76-79). One could criticize our study for evaluating only 18 cases. Since this is such a rarely reported complication, we had information on only these cases.

\section{Conclusion}

Based on the evidence presented above, the TSTT is clearly associated with the unquantifiable but definite and unacceptable risk of compromising the major radicular artery resulting in ischemic spinal cord injury leading to the devastating complication of complete permanent paralysis. Presumably safer alternative techniques for LTESI need to be embraced.

\section{Acknowledgements}

We are grateful to Dr. Manchikanti for his invaluable input in creating this manuscript. We would like to acknowledge Dr. Umeshrai Pai for his cadaveric dissections and for helping us better understand the anatomy of the lumbar neural foramen and radicular arteries during this endeavor. 


\section{References}

1. Manchikanti L, Abdi S, Atluri S, Benyamin RM, Boswell MV, Buenaventura RM, Bryce DA, Burks PA, Caraway DL, Calodney AK, Cash KA, Christo PJ, Cohen SP, Colson J, Conn A, Cordner HJ, Coubarous $S$, Datta $S$, Deer TR, Diwan SA, Falco FJE, Fellows B, Geffert SC, Grider JS, Gupta S, Hameed H, Hameed M, Hansen $H$, Helm II S, Janata JW, Justiz R, Kaye $A D$, Lee $M$, Manchikanti KN, McManus CD, Onyewu O, Parr AT, Patel VB, Racz GB, Sehgal N, Sharma M, Simopoulos TT, Singh V, Smith HS, Snook LT, Swicegood J, Vallejo R, Ward SP, Wargo BW, Zhu J, Hirsch JA. An update of comprehensive evidence-based guidelines for interventional techniques of chronic spinal pain: Part II: Guidance and recommendations. Pain Physician 2013; 16:S49-S253.

2. Manchikanti L, Buenaventura RM, Manchikanti KN, Ruan X, Gupta S, Smith HS, Christo PJ, Ward SP. Effectiveness of therapeutic lumbar transforaminal epidural steroid injections in managing lumbar spinal pain. Pain Physician 2012; 15:E199-E245.

3. Parr AT, Manchikanti L, Hameed H, Conn A, Manchikanti KN, Benyamin RM, Diwan S, Singh V, Abdi S. Caudal epidural injections in the management of chronic low back pain: A systematic appraisal of the literature. Pain Physician 2012; 15:E159-E198.

4. Benyamin RM, Manchikanti L, Parr AT, Diwan SA, Singh V, Falco FJE, Datta S, Abdi S, Hirsch JA. The effectiveness of lumbar interlaminar epidural injections in managing chronic low back and lower extremity pain. Pain Physician 2012; 15: $E_{363}-E_{404}$.

5. Diwan SA, Manchikanti L, Benyamin RM, Bryce DA, Geffert S, Hameed H, Sharma ML, Abdi S, Falco FJE. Effectiveness of cervical epidural injections in the management of chronic neck and upper extremity pain. Pain Physician 2012; 15:E405-E434.

6. Macvicar J, King W, Landers MH, Bogduk N. The effectiveness of lumbar transforaminal injection of steroids: A comprehensive review with systematic analysis of the published data. Pain Med 2013; 14:14-28.

7. Benny B, Azari P. The efficacy of lumbosacral transforaminal epidural steroid injections: A comprehensive literature review. J Back Musculoskelet Rehabil 2011; 24:67-76.

8. Datta S, Manchikanti L, Falco FJE,
Calodney AK, Atluri S, Benyamin RM, Buenaventura R, Cohen SP. Diagnostic utility of selective nerve root blocks in the diagnosis of lumbosacral radicular pain: Systematic review and update of current evidence. Pain Physician 2013; 16:SE97-SE124.

9. Shah RV. The problem with diagnostic selective nerve root blocks. Spine (Phila Pa 1976) 2012; 37:1991-1993.

10. Manchikanti L, Falco FJE, Singh V, Pampati V, Parr AT, Benyamin RM, Fellows B, Hirsch JA. Utilization of interventional techniques in managing chronic pain in the Medicare population: Analysis of growth patterns from 2000 to 2011. Pain Physician 2012; 15:E969-E982.

11. Manchikanti L, Pampati V, Falco FJE, Hirsch JA. Assessment of the growth of epidural injections in the Medicare population from 2000 to 2011. Pain Physician 2013; 16:E349-E364.

12. Manchikanti L, Pampati V, Falco FJE, Hirsch JA. Growth of spinal interventional pain management techniques: Analysis of utilization trends and Medicare expenditures 2000 to 2008. Spine (Phila Pa 1976) 2013; 38:157-168.

13. Institute of Medicine (IOM) Consensus Report. Relieving Pain in America: A Blueprint for Transforming Prevention, Care, Education, and Research, June 29, 2011.

www.iom.edu/ /media/Files/Report\%20 Files/2011/Relieving-Pain-in-America-ABlueprint-for-Transforming-PreventionCare-Education-Research/Pain\%2oResearch\%202011\%20Report\%2oBrief.pdf.

14. Martin BI, Turner JA, Mirza SK, Lee MJ, Comstock BA, Deyo RA. Trends in health care expenditures, utilization, and health status among US adults with spine problems, 1997-2006. Spine (Phila Pa 1976) 2009; 34:2077-2084.

15. Deyo RA, Mirza SK, Turner JA, Martin Bl. Overtreating chronic back pain: Time to back off? J Am Board Fam Med 2009; 22:62-68.

16. Luo X, Pietrobon R, Hey L. Patterns and trends in opioid use among individuals with back pain in the United States. Spine (Phila Pa 1976) 2004; 29:884-890.

17. Ivanova JI, Birnbaum HG, Schiller M, Kantor E, Johnstone BM, Swindle RW. Real-world practice patterns, health-care utilization, and costs in patients with low back pain: The long road to guidelineconcordant care. Spine J 2011; 11:622-632. 18. Manchikanti L, Helm II S, Fellows B,
Janata JW, Pampati V, Grider JS, Boswell MV. Opioid epidemic in the United States. Pain Physician 2012; 15:ES9-ES38.

19. Manchikanti L, Abdi S, Atluri S, Balog $\mathrm{CC}$, Benyamin RM, Boswell MV, Brown KR, Bruel BM, Bryce DA, Burks PA, Burton AW, Calodney AK, Caraway DL, Cash KA, Christo PJ, Damron KS, Datta S, Deer TR, Diwan S, Eriator I, Falco FJE, Fellows F, Geffert S, Gharibo CG, Glaser SE, Grider JS, Hameed H, Hameed $M$, Hansen $H$, Harned ME, Hayek SM, Helm II S, Hirsch JA, Janata JW, Kaye AD, Kaye AM, Kloth DS, Koyyalagunta D, Lee M, Malla Y, Manchikanti KN, McManus CD, Pampati V, Parr AT, Pasupuleti R, Patel VB, Sehgal N, Silverman SM, Singh V, Smith HS, Snook LT, Solanki DR, Tracy DH, Vallejo R, Wargo BW. American Society of Interventional Pain Physicians (ASIPP) guidelines for responsible opioid prescribing in chronic non-cancer pain: Part I - Evidence assessment. Pain Physician 2012; 15:S1-S66.

20. Manchikanti L, Abdi S, Atluri S, Balog CC, Benyamin RM, Boswell MV, Brown KR, Bruel BM, Bryce DA, Burks PA, Burton AW, Calodney AK, Caraway DL, Cash KA, Christo PJ, Damron KS, Datta S, Deer TR, Diwan S, Eriator I, Falco FJE, Fellows F, Geffert S, Gharibo CG, Glaser SE, Grider JS, Hameed H, Hameed $M$, Hansen $\mathrm{H}$, Harned ME, Hayek SM, Helm II S, Hirsch JA, Janata JW, Kaye AD, Kaye AM, Kloth DS, Koyyalagunta D, Lee $\mathrm{M}$, Malla $\mathrm{Y}$, Manchikanti KN, McManus CD, Pampati V, Parr AT, Pasupuleti $R$, Patel VB, Sehgal N, Silverman SM, Singh V, Smith HS, Snook LT, Solanki DR, Tracy DH, Vallejo R, Wargo BW. American Society of Interventional Pain Physicians (ASIPP) guidelines for responsible opioid prescribing in chronic non-cancer pain: Part 2-Guidance. Pain Physician 2012; 15:S67-S116.

21. Deyo RA, Smith DH, Johnson ES, Donovan M, Tillotson CJ, Yang X, Petrik AF, Dobscha SK. Opioids for back pain patients: Primary care prescribing patterns and use of services. J Am Board Fam Med 2011; 24:717-727.

22. Social Security Administration. Annual Statistical Report on the Social Security Disability Insurance Program 2011. Office of Research Evaluation and Statistics, Baltimore, MD, 2011.

http://www.ssa.gov/policy/docs/statcomps/di_asr/2011/di_asr11.pdf

23. Pinto RZ, Maher CG, Ferreria ML, Hancock M, Oliveira VC, McLachlan AJ, Koes 
B, Ferreira PH. Epidural corticosteroid injections in the management of sciatica: A systematic review and meta-analysis. Ann Intern Med 2012; 157:865-877.

24. Manchikanti L, Singh V, Caraway DL, Benyamin RM, Hirsch JA. Medicare physician payment systems: Impact of 2011 schedule on interventional pain management. Pain Physician 2011; 14:E5-E33.

25. Manchikanti L, Hirsch JA. Medicare physician payment rules for 2011: A primer for the neurointerventionalist. ] Neurointervent Surg 2011; 3:399-402.

26. Manchikanti L, Singh V, Caraway DL, Benyamin RM, Falco FJE, Hirsch JA. Physician payment outlook for 2012: Déjà Vu. Pain Physician 2012; 15:E27-E52.

27. Manchikanti L, Parr AT, Singh V, Fellows B. Ambulatory surgery centers and interventional techniques: A look at long-term survival. Pain Physician 2011; 14:E177-E215.

28. U.S. Department of Health and Human Services. Office of Inspector General (OIG). Medicare Payments for Facet Joint Injection Services (OEI-05-0700200). September 2008.

http://www.oig.hhs.gov/oei/reports/oei05-07-00200.pdf

29. Deyo RA, Mirza SK, Martin BI, Krueter W, Goodman DC, Jarvik JG. Trends, major medical complications, and charges associated with surgery for lumbar spinal stenosis in older adults. JAMA 2010; 303:1259-1265.

30. Rajaee SS, Bae HW, Kanim LE, Delamarter RB. Spinal fusion in the United States: Analysis of trends from 1998 to 2008. Spine (Phila Pa 1976) 2012; 37:67-76.

31. Deyo RA, Martin BI, Kreuter W, Jarvik JG, Angier H, Mirza SK. Revision surgery following operations for lumbar stenosis. J Bone Joint Surg Am 2011; 93:1979-1986.

32. Chou R, Huffman L. Guideline for the Evaluation and Management of Low Back Pain: Evidence Review. American Pain Society, Glenview, IL, 2009.

www.americanpainsociety.org/uploads/ pdfs/LBPEvidRev.pdf

33. Hansen H, Manchikanti L, Simopoulous TT, Christo PJ, Gupta S, Smith HS, Hameed $\mathrm{H}$, Cohen SP. A systematic evaluation of the therapeutic effectiveness of sacroiliac joint interventions. Pain Physician 2012; 15:E247-E278.

34. Manchikanti L, Benyamin RM, Falco FJE, Caraway DL, Datta S, Hirsch JA. Guidelines warfare over interventional techniques: Is there a lack of discourse or straw man? Pain Physician 2012; 15:E1-E26.

35. Manchikanti L, Giordano J, Fellows B, Hirsch JA. Placebo and nocebo in interventional pain management: $A$ friend or a foe - or simply foes? Pain Physician 2011; 14:E157-E175.

36. Manchikanti L, Benyamin RM, Swicegood JR, Falco FJE, Datta S, Pampati V, Fellows B, Hirsch JA. Assessment of practice patterns of perioperative management of antiplatelet and anticoagulant therapy in interventional pain management. Pain Physician 2012; 15:E955-E968.

37. Manchikanti L, Malla Y, Wargo BW, Cash KA, Pampati V, Fellows B. A prospective evaluation of complications of 10,000 fluoroscopically directed epidural injections. Pain Physician 2012; 15:131-140.

38. Manchikanti L, Cash KA, McManus CD, Pampati V. Fluoroscopic caudal epidural injections in managing chronic axial low back pain without disc herniation, radiculitis or facet joint pain. J Pain Res 2012; 5:381-390.

39. Manchikanti L, Singh V, Cash KA, Pampati V, Damron KS, Boswell MV. Effect of fluoroscopically guided caudal epidural steroid or local anesthetic injections in the treatment of lumbar disc herniation and radiculitis: A randomized, controlled, double blind trial with a two-year follow-up. Pain Physician 2012; 15:273-286.

40. Manchikanti L, Singh V, Cash KA, Pampati V, Datta S. Fluoroscopic caudal epidural injections in managing post lumbar surgery syndrome: Two-year results of a randomized, double-blind, active-control trial. Int J Med Sci 2012; 9:582-591.

41. Manchikanti L, Cash KA, McManus CD, Pampati V, Fellows B. Results of 2-year follow-up of a randomized, doubleblind, controlled trial of fluoroscopic caudal epidural injections in central spinal stenosis. Pain Physician 2012; 15:371-384.

42. Manchikanti L, Singh V, Cash KA, Pampati V, Falco FJE. The role of fluoroscopic interlaminar epidural injections in managing chronic pain of lumbar disc herniation or radiculitis: A randomized, double-blind trial. Pain Pract 2012 Dec. 27. [Epub ahead of print]

43. Manchikanti L, Cash KA, McManus CD, Pampati V, Benyamin R. Fluoroscopic lumbar interlaminar epidural injec- tions in managing chronic lumbar axial or discogenic pain. J Pain Res 2012; 5:301-311.

44. Manchikanti L, Cash KA, McManus CD, Damron KS, Pampati V, Falco FJE. Lumbar interlaminar epidural injections in central spinal stenosis: Preliminary results of a randomized, double-blind, active control trial. Pain Physician 2012; 15:51-63.

45. Manson NA, McKeon MD, Abraham EP. Transforaminal epidural steroid injections prevent the need for surgery in patients with sciatica secondary to lumbar disc herniation: A retrospective case series. Can J Surg 2013; 56:89-96.

46. Houten JK, Errico TJ. Paraplegia after lumbosacral nerve root block: Report of three cases. Spine ] 2002; 2:70-75.

47. Huntoon MA, Martin DP. Paralysis after transforaminal epidural injection and previous spinal surgery. Reg AnesthPain Med 2004; 29:494-495.

48. Glaser SE, Falco F. Paraplegia following a thoracolumbar transforaminal epidural steroid injection. Pain Physician 2005; 8:309-314.

49. Somayaji HS, Saifuddin A, Casey ATH, Briggs TWR. Spinal cord infarction following therapeutic computed tomography-guided left $\mathrm{I}_{2}$ nerve root injection. Spine (Phila Pa 1976) 2005; 30:E106-E108.

50. Quintero N, Laffont I, Bouhmidi L, Rech C, Schneider AE, Gavardin T, Dizien O. Transforaminal epidural steroid injection and paraplegia: Case report and bibliographic review. Ann Readapt Med Phys 2006; 49:242-247.

51. Kennedy DJ, Dreyfuss P, Aprill CN, Bogduk N. Paraplegia following imageguided transforaminal lumbar spine epidural steroid injection: Two case reports. Pain Med 2009; 10:1389-1394.

52. Lyders EM, Morris PP. A case of spinal cord infarction following lumbar transforaminal epidural steroid injection: MR imaging and angiographic findings. AJNR Am J Neuroradiol 2009; 30:1691-1693.

53. Wybier M, Gaudart S, Petrover D, Houdart E, Laredo JD. Paraplegia complicating selective steroid injections of the lumbar spine: Report of five cases and review of the literature. Eur Radiol 2010; 20:181-189.

54. Glaser SE, Shah RV. Root cause analysis of paraplegia following transforaminal epidural steroid injections: The 'unsafe' triangle. Pain Physician 2010; 13:237-244. 
55. Murthy NS, Maus TP, Behrns CL. Intraforaminal location of the great anterior radiculomedullary artery (artery of Adamkiewicz): A retrospective review. Pain Med 2010; 11:1756-1764.

56. Chang Chien GC, Candido KD, Knezevic NN. Digital subtraction angiography does not reliably prevent paraplegia associated with lumbar transforaminal epidural steroid injection. Pain Physician 2012; 15:515-523.

57. Alleyne $\mathrm{CH}$ Jr, Cawley CM, Shengelaia $\mathrm{GG}$, Barrow DL. Microsurgical anatomy of the artery of Adamkiewicz and its segmental artery. J Neurosurg 1998; 89:791-795.

58. Kroszczynski AC, Kohan K, Kurowski $M$, Olson TR, Downie SA. Intraforaminal location of thoracolumbar anterior medullary arteries. Pain Med 2013; [Epub ahead of print].

59. Rauschning W. Normal and pathological anatomy of the nerve root canals. Spine (Phila Pa 1976) 1987; 2:1008-1019.

6o. van Roy P, Barbaix E, Clarijs JP, Mense S. Anatomical background of low back pain: Variability and degeneration of the lumbar spinal canal and intervertebral disc. Schmerz 2001; 15:418-424.

61. Takase K, Sawamura Y, Igarashi K, Chiba Y, Haga K, Saito H, Takahashi S. Demonstration of the artery of Adamkiewicz at multi-detector row helical CT. Radiology 2002; 223:39-45.

62. Jasper J. Lumbar retrodiscal transforaminal injection. Pain Physician 2007; 10:501-510.

63. Lee IS, Kim SH, Lee JW, Hong SH, Choi JY, Kang HS, Song JW, Kwon AK. Comparison of the temporary diagnostic relief of transforaminal epidural steroid injection approaches: Conventional versus posterolateral technique. AJNR Am J
Neuroradiol 2007; 28:204-208.

64. Zhu J, Falco FJ, Formoso F, Onyewu $\mathrm{CO}$,Irwin FL. Alternative approach for lumbar transforaminal epidural steroid injections. Pain Physician 2011; 14:331-341.

65. Park KD, Lee J, Jee H, Park Y. Kambin triangle versus the supraneural approach for the treatment of lumbar radicular pain. Am J Phys Med Rehabil 2012; 91:1039-1050.

66. Park JW, Nam HS, Cho SK, Jung HJ, Lee BJ, Park Y. Kambin's triangle approach of lumbar transforaminal epidural injection with spinal stenosis. Ann Rehabi Med 2011; 35:833-843.

67. Kim C, Moon CJ, Choi HE, Park Y. Retrodiscal approach of lumbar epidural block. Ann Rehabil Med 2011; 35:418-426.

68. Park JW, Nam HS, Park Y. Usefulness of posterolateral transforaminal approach in lumbar radicular pain. Ann Rehabil Med 2011; 35:395-404.

69. Park CH, Lee SH, Park HS. Lumbar retrodiscal versus post-ganglionic transforaminal epidural steroid injection for the treatment of lumbar intervertebral disc herniations. Pain Physician 2011; 14:353-360.

70. Desai MJ, Shah B, Sayal PK. Epidural contrast flow patterns of transforaminal epidural steroid injections stratified by commonly used final needle-tip position. Pain Med 2011; 12:864-870.

71. Raghavendra M, Patel V. Should we cease performing transforaminal injections? Reg Anesth Pain Med 2005; 30:207-208.

72. Lazorthes G, Gouaze A, Zadeh JO, Santini JJ, Lazorthes Y, Burdin P. Arterial vascularization of the spinal cord. Recent studies of the anastomotic substitution pathways. J Neurosurg 1971; 35:253-262.
73. Lee $M H$, Yang KS, Kim YH, Jung HD, Lim SJ, Moon DE. Accuracy of live fluoroscopy to detect intravascular injection during lumbar transforaminal epidural injections. Korean J Pain 2010; 23:18-23.

74. Manchikanti L, Cash KA, Pampati V, Damron KS, McManus CD. Evaluation of lumbar transforaminal epidural injections with needle placement and contrast flow patterns: A prospective, descriptive report. Pain Physician 2004; 7:217-223.

75. Furman MB, O'Brien EM, Zgleszewski TM. Incidence of intravascular penetration in transforaminal lumbosacral epidural steroid injections. Spine (Phila Pa 1976) 2000; 25:2628-2632.

76. Gharibo CG, Varlotta GP, Rhame EE, Liu EC, Bendo JA, Perloff MD. Interlaminar versus transforaminal epidural steroids for the treatment of subacute lumbar radicular pain: A randomized, blinded, prospective outcome study. Pain Physician 2011; 14:499-511.

77. Rados I, Sakic K, Fingler M, Kapural L. Efficacy of interlaminar vs transforaminal epidural steroid injection for the treatment of chronic unilateral radicular pain: prospective, randomized study. Pain Med 2011; 12:1316-1321.

78. Smith CC, Booker T, Schaufele MK, Weiss P. Interlaminar versus transforaminal epidural steroid injections for the treatment of symptomatic lumbar spinal stenosis. Pain Med 2010; 11:1511-1515.

79. Lee JH, An JH, Lee SH. Comparison of the effectiveness of interlaminar and bilateral transforaminal epidural steroid injections in treatment of patients with lumbosacral disc herniation and spinal stenosis. Clin J Pain 2009; 25:206-210. 